\title{
Genetic network profiles associated with established resistance to ionizing radiation in acute promyelocytic leukemia cells and their extracellular vesicles
}

\author{
SATORU MONZEN $^{1}$, MITSURU CHIBA ${ }^{2}$ and YOICHIRO HOSOKAWA ${ }^{1}$ \\ Departments of ${ }^{1}$ Radiological Life Sciences and ${ }^{2}$ Biomedical Sciences, Division of Medical Life Sciences, \\ Hirosaki University Graduate School of Health Sciences, Hirosaki, Aomori 036-8564, Japan
}

Received July 31, 2015; Accepted September 23, 2015

DOI: $10.3892 /$ or.2015.4471

\begin{abstract}
Radiation-resistant acute promyelocytic leukemia (APL) cells present challenges to treatment, and the acquisition of resistance to ionizing radiation (IR) is a matter of clinical concern. However, little information is available on the behavior of radio-resistant APL in terms of gene expression profiles and intercellular communication. In this study, cDNA microarray and RT-PCR were used to analyze the intracellular genetic network and extracellular vesicles (EVs), respectively, in the established radio-resistant HL60 (Res-HL60) cell line. Significant changes in the expression of 7,309 known mRNAs were observed in Res-HL60 relative to control. In addition, 7 mRNAs were determined as targets because significant changes in the expression were observed using Ingenuity analysis software, confirming the quantitative RT-PCR. However, EVs from Res-HL60 cells did not include these target molecules. These results suggest that radio-resistant APL is regulated by the expression and suppression of specific molecules, and these molecules are not transferred between cells by EVs.
\end{abstract}

\section{Introduction}

Acute leukemia treatment mainly comprises full myelo-ablation, including leukemic cells, via chemotherapy and/or total body irradiation; subsequent hematopoietic stem cell transplantation is performed to reconstruct the hematopoietic system (1-3). However, although rare, repeated exposure to ionizing radiation (IR) can produce other leukemic cells and/or radio-resistant leukemic cells and thus presents an obstacle

Correspondence to: Dr Satoru Monzen, Department of Radiological Life Sciences, Division of Medical Life Sciences, Hirosaki University Graduate School of Health Sciences, 66-1 Hon-cho, Hirosaki, Aomori 036-8564, Japan

E-mail: monzens@hirosaki-u.ac.jp

Key words: radiation resistance, acute promyelocytic leukemia, cDNA microarray, intracellular genetic network, extracellular vesicles to treatment against treatment $(4,5)$. Acute promyelocytic leukemia (APL) is a unique subtype of acute myeloid leukemia (AML), characterized by a block at the promyelocytic stage of hematopoiesis $(6,7)$.

Our previous study demonstrated that a model of radiation-resistant APL (Res-HL60 cells) exhibited a high repair capacity with normally functioning ATM/ATR and DNA-dependent protein kinase (5); furthermore, these cells exhibit resistance to phorbol 12-myristate 13-acetate-induced monocyte differentiation (8). However, little information is available regarding the behavior of radio-resistant APL in terms of gene expression profiles and intercellular communication. Our present study investigated the characteristic mRNA patterns in Res-HL60 and the transfer of related molecules between cells. Recently, attention has focused on extracellular vesicles (EVs; <200 nm $\phi$ ), which transfer intracellular components and maintain intercellular communication (9). It is important to demonstrate clearly whether radio-resistant behavior is maintained independently or via intercellular communication when considering leukemic treatment strategies.

In this study, an mRNA expression analysis of both intracellular and EV material was performed to clarify the genetic network and target gene(s) in Res-HL60.

\section{Materials and methods}

Cell preparation and culture. The human APL cell line HL60 (Wt-HL60) was purchased from RIKEN BioResource Center (Tsukuba, Japan). The Res-HL60 cell line was established by subjecting Wt-HL60 to $4 \mathrm{~Gy}$ of X-irradiation/week for 4 weeks. Approximately $2 \%$ surviving fraction of wt-HL60 cells was shown following initial exposure of 4 Gy. Wt-HL60 and Res-HL60 were maintained in RPMI-1640 medium (Life Technologies, Carlsbad, CA, USA) supplemented with $10 \%$ heat-inactivated fetal bovine serum (FBS; Japan Bioserum, Hiroshima, Japan) and $1 \%$ penicillin/streptomycin (Life Technologies) in a humidified atmosphere at $37^{\circ} \mathrm{C}$ and $5 \%$ $\mathrm{CO}_{2}$.

Irradiation. X-ray irradiation $(150 \mathrm{kVp}, 20 \mathrm{~mA}$ with $0.5-\mathrm{mm}$ aluminum and $0.3-\mathrm{mm}$ copper filters) was performed using an 
Table I. Primers and accession numbers in the focused genes.

\begin{tabular}{|c|c|c|c|c|}
\hline Primer name & Accession no. & Sequence $\left(5^{\prime}-3^{\prime}\right)$ & Size (nt) & Amplication size (bp) \\
\hline $\begin{array}{l}\text { SEPT11-forward } \\
\text { SEPT11-reverse }\end{array}$ & NM_018243 & $\begin{array}{l}\text { GAAAGCAGCGGCTCAGTTA } \\
\text { GGCTTGCCAGGCTTTATGT }\end{array}$ & $\begin{array}{l}19 \\
19\end{array}$ & 110 \\
\hline $\begin{array}{l}\text { MAD2L1-forward } \\
M A D 2 L 1 \text {-reverse }\end{array}$ & NM_002358 & $\begin{array}{l}\text { GCGTGCTTTTGTTTGTGTC } \\
\text { TAAAATGCTGTTGATGCCG }\end{array}$ & $\begin{array}{l}19 \\
19\end{array}$ & 122 \\
\hline $\begin{array}{l}V A S P \text {-forward } \\
V A S P \text {-reverse }\end{array}$ & NM_003370 & $\begin{array}{l}\text { ACCTGGTCGGTCCCGAAC } \\
\text { GGAGACCCGGCGCTCTATG }\end{array}$ & $\begin{array}{l}18 \\
19\end{array}$ & 96 \\
\hline $\begin{array}{l}M X D 1 \text {-forward } \\
M X D 1 \text {-reverse }\end{array}$ & NM_002357.2 & $\begin{array}{l}\text { AGCTGGGCATTGAGAGGAT } \\
\text { CCACGTCAACGTCGATTT }\end{array}$ & $\begin{array}{l}19 \\
18\end{array}$ & 96 \\
\hline $\begin{array}{l}R N F 2 \text {-forward } \\
R N F 2 \text {-reverse }\end{array}$ & NM_001846.2 & $\begin{array}{l}\text { GCGTCCGCGGCAGCTGATA } \\
\text { ATTGCGGCTCCTGCCCCAG }\end{array}$ & $\begin{array}{l}19 \\
19\end{array}$ & 77 \\
\hline $\begin{array}{l}\text { CCND1-forward } \\
C C N D 1 \text {-reverse }\end{array}$ & NM_001725.2 & $\begin{array}{l}\text { CGAGAAGCTGTGCATCTACACC } \\
\text { ACTTGAGCTTGTTCACCAGGAG }\end{array}$ & $\begin{array}{l}22 \\
22\end{array}$ & 86 \\
\hline $\begin{array}{l}C S E 1 L \text {-forward } \\
C S E 1 L \text {-reverse }\end{array}$ & NM_001846.2 & $\begin{array}{l}\text { TTCAGAAGCAGTTAAGTGATGCA } \\
\text { GCAAGTCAGGCCATTTCTGT }\end{array}$ & $\begin{array}{l}23 \\
20\end{array}$ & 72 \\
\hline $\begin{array}{l}\text { ITPKA-forward } \\
\text { ITPKA-reverse }\end{array}$ & NM_001093772.1 & $\begin{array}{l}\text { CGACCTGCTGAGCGACAGT } \\
\text { CGGATCTTCTGCCAGTGGT }\end{array}$ & $\begin{array}{l}19 \\
19\end{array}$ & 96 \\
\hline $\begin{array}{l}T N F \text {-forward } \\
T N F \text {-reverse }\end{array}$ & NM_000860 & $\begin{array}{l}\text { CAGCCTCTTCTCCTTCCTGA } \\
\text { GGCCAGAGGGCTGATTAGA }\end{array}$ & $\begin{array}{l}20 \\
19\end{array}$ & 124 \\
\hline $\begin{array}{l}H P G D \text {-forward } \\
H P G D \text {-reverse }\end{array}$ & NM_001725.2 & $\begin{array}{l}\text { GAACCTCAGAAGACTCTGTTCATC } \\
\text { CATTATTGACCAAAATGTCCAGTC }\end{array}$ & $\begin{array}{l}24 \\
24\end{array}$ & 115 \\
\hline $\begin{array}{l}G A P D H \text {-forward } \\
G A P D H \text {-reverse }\end{array}$ & NM_002046 & $\begin{array}{l}\text { GCCACATCGCTCAGACACC } \\
\text { AGGCGCCCAATACGACCA }\end{array}$ & $\begin{array}{l}19 \\
18\end{array}$ & 69 \\
\hline
\end{tabular}

Primer pairs were designed using exon regions of human-specific sequences that sandwiched introns. Therefore, bovine mRNAs in FBS and genomic DNA sequences were not detected.

X-ray generator (MBR-1520R-3; Hitachi Medical Co., Ltd., Tokyo, Japan), with a distance of $45 \mathrm{~cm}$ between the focus and target. The dose was monitored with a thimble ionization chamber placed next to the sample during irradiation. The dose rate was $1 \mathrm{~Gy} / \mathrm{min}$.

cDNA microarray analysis. To compare the mRNA expression profiles of Res-HL60 and Wt-HL60 cells, a two-color mRNA microarray method was performed. Total RNAs were extracted using an RNeasy isolation kit (Qiagen, Hilden, Germany). Total RNA quality was confirmed using a 2100 Bioanalyzer (Agilent Technologies, Santa Clara, CA, USA). mRNAs were labeled using $\mathrm{Cy} 3$ and $\mathrm{Cy} 5$ mono-reactive dyes (GE Healthcare, Buckinghamshire, UK). Labeling reactions were performed using $1 \mu \mathrm{g}$ of total RNA and an Amino Allyl aRNA kit (Life Technologies). Microarray analyses were performed using a Toray mRNA microarray system (3D-Gene Scanner 3000 system; Toray, Tokyo, Japan).

EV isolation and RNA extraction. Cell culture media were centrifuged at $2,000 \mathrm{x}$ g for $15 \mathrm{~min}$ and $4^{\circ} \mathrm{C}$ to remove cell debris. The supernatants were then passed through a $0.22-\mu \mathrm{m}$ filter. The filtrates were ultracentrifuged at $120,000 \mathrm{x} \mathrm{g}$ for $70 \mathrm{~min}$ and $4^{\circ} \mathrm{C}$ on an Optima TLX Ultracentrifuge (Beckman Coulter, Brea, CA, USA) to collect EVs. Total RNA was extracted from EVs or cells using an ISOGEN II (Nippon Gene, Tokyo, Japan) according to the manufacturer's instructions.
Reverse transcription-polymerase chain reaction (RT-PCR). To synthesize cDNAs from cells or EVs, high-capacity cDNA reverse transcriptase kits (Life Technologies) were used. The synthesized cDNAs were then subjected to PCR in a $15 \mu \mathrm{l}$ reaction mixture containing $1 \mathrm{X}$ Power SYBR Green Master Mix (Life Technologies), $0.5 \mu \mathrm{M}$ concentrations of the primer pairs described in Table I, and cDNA template. Primer pairs were designed from human-specific sequence regions. Therefore, potential bovine mRNA contamination in FBS was not detected. Quantitative PCR was performed using real-time PCR system (StepOne Plus; Life Technologies) under the following conditions: $10 \mathrm{~min}$ at $95^{\circ} \mathrm{C}$, followed by 40 cycles each of $95^{\circ} \mathrm{C}$ for $15 \mathrm{sec}$, and $60^{\circ} \mathrm{C}$ for $60 \mathrm{sec}$. GAPDH mRNA was used as an internal control. Cellular expression values and standard deviations were calculated by the comparative $\mathrm{C}_{\mathrm{t}}$ method, and values were normalized according to the values from Wt-HL60 cells, which were set at 1.0. PCR products derived from the mRNA of EVs were electrophoresed on $4 \%$ agarose gels. Detection of amplified fragments was achieved via ethidium bromide staining using a ChemiDoc XRS and Quantity One software (both from Bio-Rad).

Statistics. Statistical analysis was performed using the Origin software package (OriginLab ${ }^{\circledR}$ Pro version 9.0; OriginLab Co., Northampton, MA, USA) and SPSS version 17.0 for Windows (IBM, Chicago, IL, USA). Statistical analysis of the cDNA microarray was performed using Ingenuity ${ }^{\circledR}$ Pathway Analysis 
Table II. Significant differences in all known mRNAs in the cDNA microarray.

\begin{tabular}{lc} 
Contents & No. of genes \\
\hline Total number of target genes in collected data & 25,000 \\
Number of known genes $^{\mathrm{a}}$ in target genes & 12,245 \\
Significantly changing genes in known genes $^{\text {(Res vs. Wt) }}$ & 7,309 \\
Mapped by Ingenuity $^{\circledR}$ in significant genes & 4,268 \\
\hline
\end{tabular}

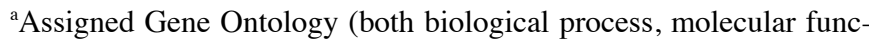
tion, and biological process). ${ }^{\text {b}} \mathrm{P}<0.05$, Student's t-test.

tools (Qiagen Silicon Valley, Redwood City, CA, USA); a $\mathrm{P}$-value $<0.05$ was considered statistically significant.

\section{Results}

Expression network of mRNA in human Res-HL60. In order to clarify the mRNA expression profile in Res-HL60 cells, a cDNA microarray analysis and Ingenuity ${ }^{\circledR}$ statistical analysis were performed. Res-HL60 cells, which show resistance to radiation, were extracted from total RNAs at high quality and sufficient concentration (Fig. 1). A total of $25 \mathrm{k}$ target molecules were exported, and 7,309 known molecules were identified as significantly upregulated or downregulated in comparison to wild-type control cells (Wt-HL60) (Table II). Of these molecules, 4,268 were uploaded to Ingenuity ${ }^{\circledR}$ for functional analysis. According to the canonical pathway analysis of Res-HL60 by Ingenuity ${ }^{\circledR}$, significant changes were observed in the top 4 categories of 'protein ubiquitination pathway', 'nucleotide excision repair pathway', 'assembly of RNA polymerase II complex', and 'TCA cycle II' relative to Wt-HL60 [the- $\log$ (p-value) for each pathway was 8.6, 8.0, 4.3, and 4.0, respectively] (Fig. 2A). In addition, the 'protein ubiquitination pathway' category featured the greatest number of affected molecules (Fig. 2B).

Based on the above information, a biofunctional analysis of the Ingenuity ${ }^{\circledR}$ heat map revealed that the genetic categories of 'cancer', 'cell death and survival', 'cell cycle', 'small molecule biochemistry', 'cellular assembly', and 'organization and infection' correlated strongly in this order (Fig. 3A). In addition, various molecules in the categories of 'cancer,' 'cell death and survival', were particularly observed in Res-HL60 relative to Wt-HL60 (Fig. 3B).

Quantitative $m R N A$ expression analysis. To identify the target mRNA(s) related to radio-resistance, a quantitative expression analysis of mRNAs in the top 4 categories (e.g., 'cell cycle', 'DNA replication', 'cell death and survival', and 'infection') was performed. As shown in Table III, Res-HL60 exhibited significantly increased expression of the cell cycle-related mRNAs SEPT11, MAD2L1, and CHFR (6.97-, 5.05- and 3.54-fold, respectively) and significantly decreased expression of MCPH1, VASP, and MXD1 (0.59-, 0.54- and 0.21-fold, respectively) relative to $\mathrm{Wt}-\mathrm{HL} 60$. Expression of the DNA replication-related mRNAs $R N F 2$, SIRT1, and RNF4 was
Table III. Analysis of significant expression of mRNA in cDNA microarray.

\begin{tabular}{|c|c|c|c|}
\hline Gene name & Accession no. & Prediction $^{\mathrm{a}}$ & Ratio (Res/W \\
\hline \multicolumn{4}{|c|}{ Cell cycle-related mRNAs } \\
\hline SEPT11 & NM_018243 & Activated & $6.97 \pm 2.14$ \\
\hline$M A D 2 L 1$ & NM_002358 & Activated & $5.05 \pm 0.81$ \\
\hline CHFR & NM_018223.1 & Activated & $3.54 \pm 1.61$ \\
\hline МСРHI & NM_024596.2 & Inhibited & $0.59 \pm 0.02$ \\
\hline$V A S P$ & NM_003370 & Inhibited & $0.54 \pm 0.02$ \\
\hline$M X D 1$ & NM_002357.2 & Inhibited & $0.21 \pm 0.04$ \\
\hline
\end{tabular}

DNA replication-related $\mathrm{mRNAs}$

$\begin{array}{llll}R N F 2 & \text { NM_007212.3 } & \text { Activated } & 5.41 \pm 2.44 \\ \text { SIRT1 } & \text { NM_012238.4 } & \text { Activated } & 4.24 \pm 2.26 \\ R N F 4 & \text { NM_002938.3 } & \text { Activated } & 3.86 \pm 1.63 \\ \text { LIG1 } & \text { NM_000234 } & \text { Inhibited } & 0.55 \pm 0.05 \\ \text { TDRD7 } & \text { NM_014290 } & \text { Inhibited } & 0.53 \pm 0.04 \\ \text { CCND1 } & \text { NM_053056 } & \text { Inhibited } & 0.15 \pm 0.02\end{array}$

Cell death and survival-related mRNAs

$\begin{array}{llll}\text { COLAA2 } & \text { NM_001846.2 } & \text { Activated } & 35.2 \pm 8.43 \\ K I T & \text { NM_001093772.1 } & \text { Activated } & 24.7 \pm 11.8 \\ I G F B P 7 & \text { NM_001553 } & \text { Activated } & 23.2 \pm 9.46 \\ P R G 2 & \text { NM_002728 } & \text { Inhibited } & 0.06 \pm 0.03 \\ \text { HPGD } & \text { NM_000860 } & \text { Inhibited } & 0.05 \pm 0.02 \\ B P I & \text { NM_001725.2 } & \text { Inhibited } & 0.04 \pm 0.01\end{array}$

Infection-related mRNAs

$\begin{array}{llll}\text { CSE1L } & \text { NM_001316.2 } & \text { Activated } & 10.9 \pm 5.37 \\ \text { ITPKA } & \text { NM_002220 } & \text { Activated } & 7.30 \pm 1.72 \\ \text { GBAS } & \text { NM_001483 } & \text { Activated } & 6.43 \pm 1.61 \\ \text { CRIPAK } & \text { NM_175918 } & \text { Inhibited } & 0.27 \pm 0.02 \\ E G R 1 & \text { NM_001964 } & \text { Inhibited } & 0.19 \pm 0.04 \\ T N F & \text { NM_000594 } & \text { Inhibited } & 0.19 \pm 0.07\end{array}$

Statistical analysis was performed using Ingenuity ${ }^{\circledR}$. ${ }^{\text {aPrediction state }}$ of target gene from downstream molecules is shown as 'Activated' ( $>2.00$ of Z-score) or 'Inhibited' (<-2.00 of z-score).

significantly higher (5.41-, 4.24- and 3.86-fold, respectively) and that of $L I G 1, T D R D 7$, and CCND1 significantly lower (0.55-, 0.53- and 0.15-fold, respectively) in Res-HL60 relative to Wt-HL60. Expression of the cell death and survival-related mRNAs COL4A2, KIT, and IGFBP7 was higher (35.2-, 24.7- and 23.2-fold, respectively) and that of PRG2, HPGD, and BPI significantly lower (0.06-, 0.05- and 0.04-fold, respectively) in Res-HL60 than in Wt-HL60. Expression of the infection-related mRNAs CSE1L, ITPKA, and GBAS was significantly higher (10.9-, 7.30- and 6.43-fold, respectively) and that of CRIPAK, EGRI, and TNF significantly lower (0.27-, 0.19- and 0.19-fold, respectively) in Res-HL60 than in Wt-HL60.

The reproducibility of these mRNA expression results was confirmed using real-time RT-PCR. Ten primers for verification of sufficient accuracy were prepared (Table I). RT-PCR detected upregulation of SEPT11 and ITPKA and down- 

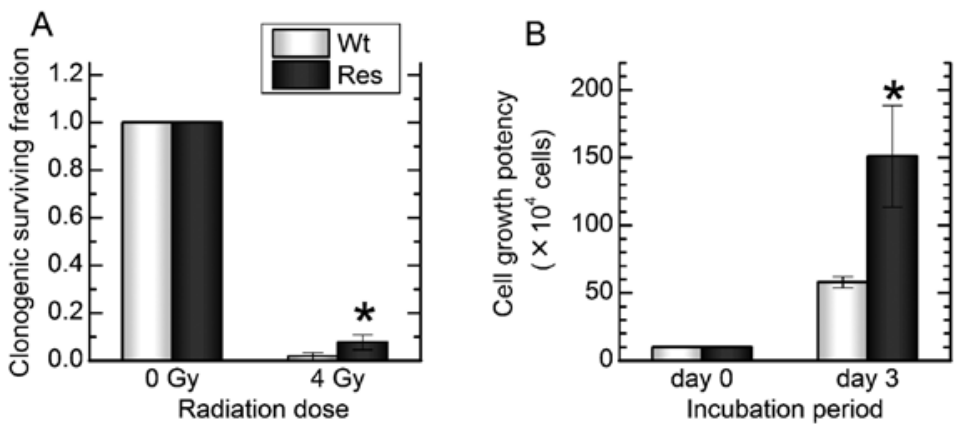

C

D
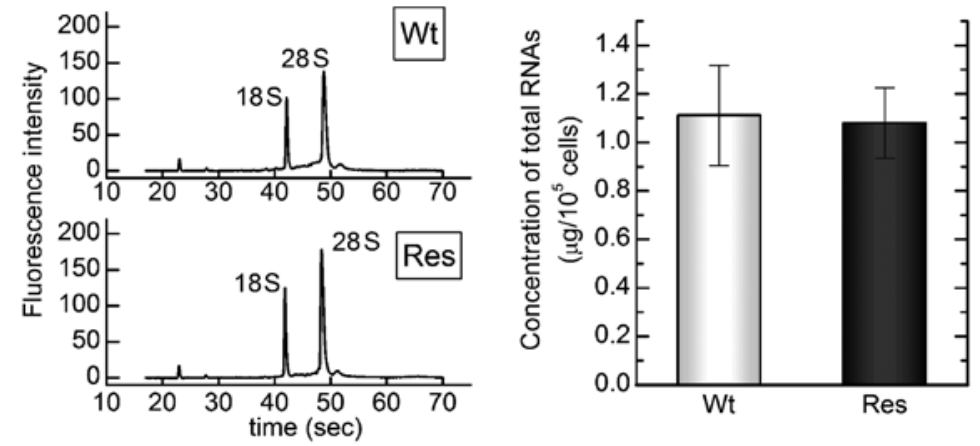

Figure 1. The characteristics of the surviving Res-HL60 cells. Surviving fraction of clonogenic cells (A), potential of cell growth (B), quality of extracted total RNAs (C) and concentration of total RNAs (D) were observed. Values are shown as means \pm standard errors of 3 separate experiments. "P $<0.05$ vs. 0 Gy (A) or vs. day 0 (B).

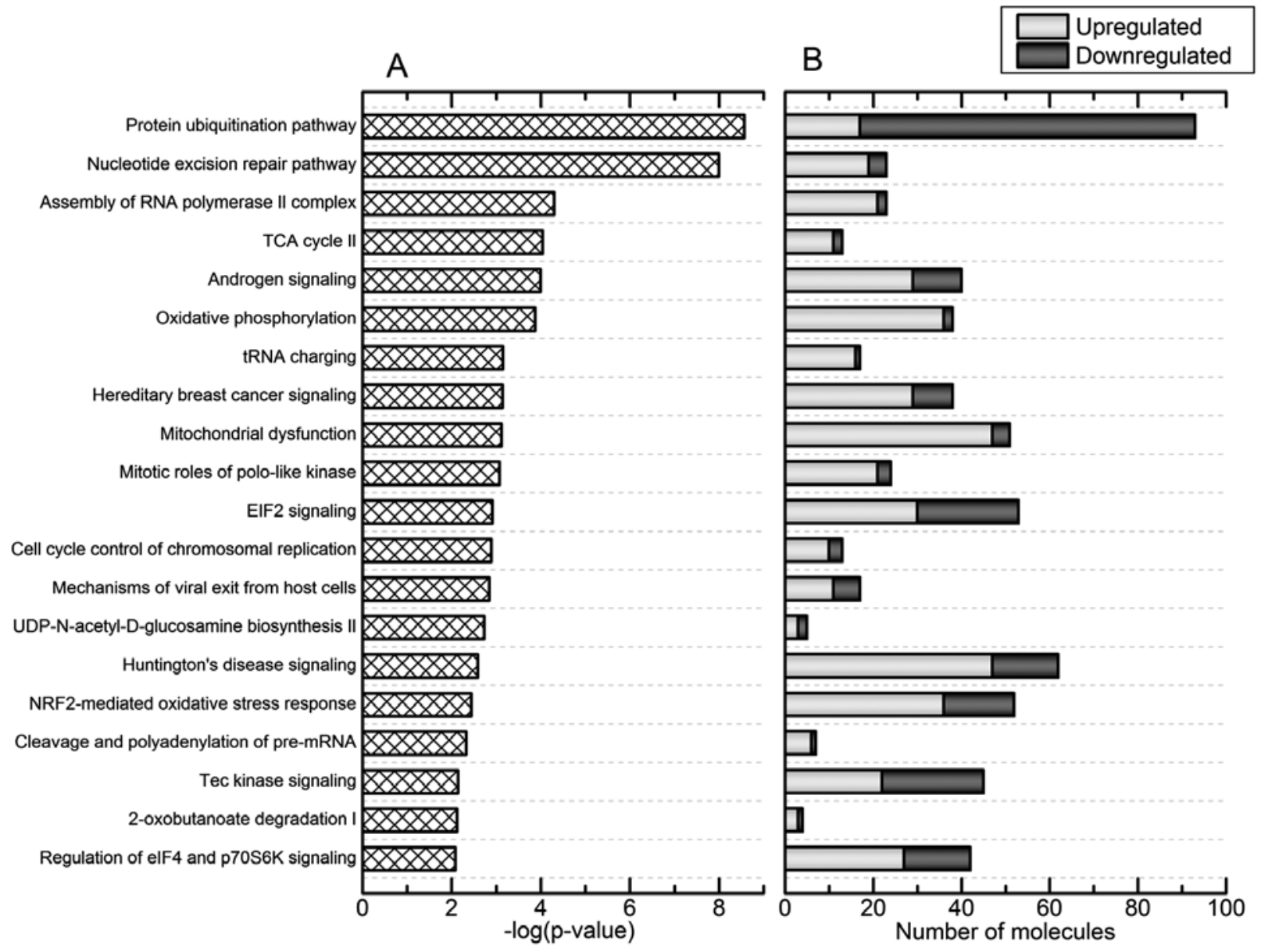

Figure 2. Top 20 canonical pathways and number of significant molecules in Res-HL60. The p-value of each canonical pathway (A) and the number of molecules with significant variance (B) according to comprehensive mRNA expression analysis using Ingenuity ${ }^{\circledast}$ Pathway Analysis tools are shown. The numbers of both upregulated and downregulated genes are shown in white and black columns, respectively. 


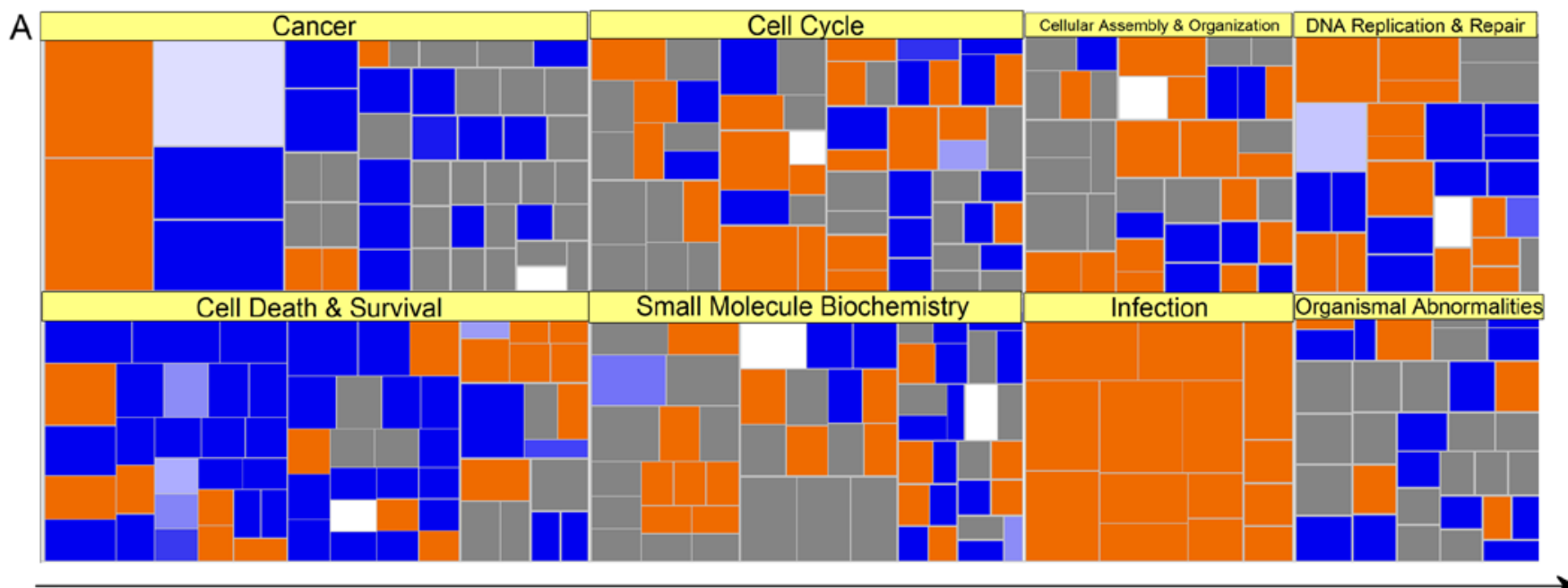

Size by p-value

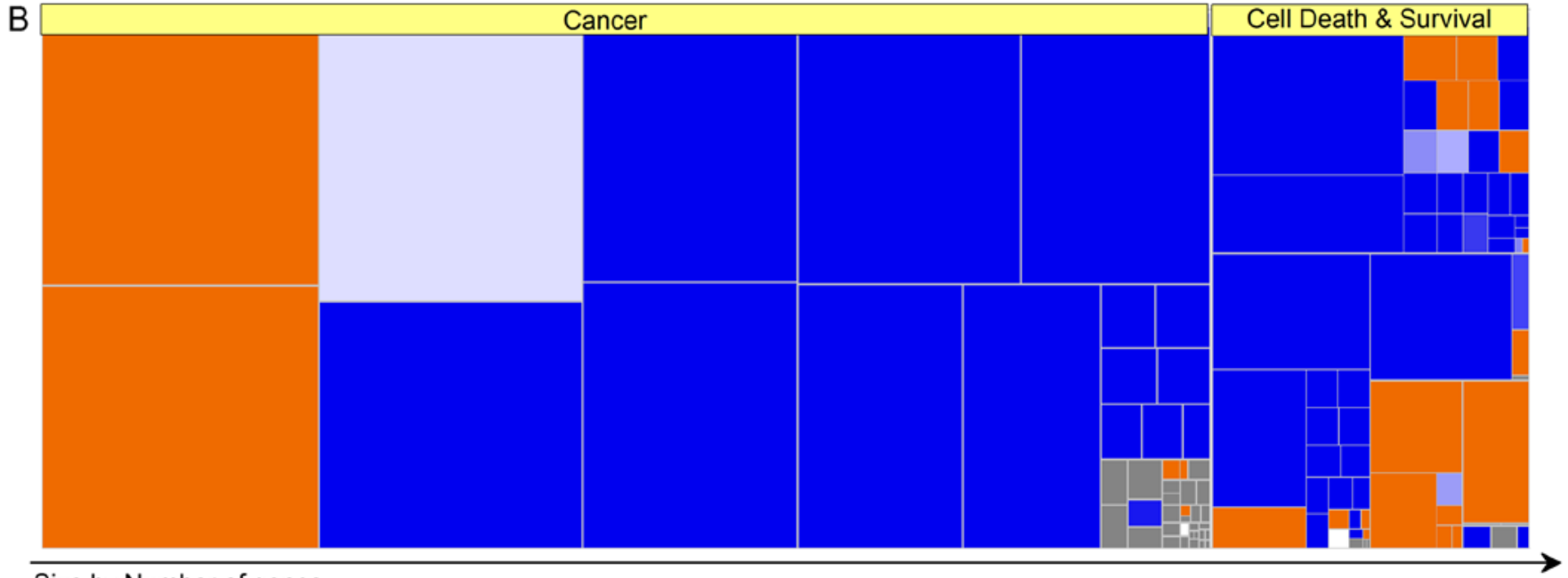

Size by Number of genes

Figure 3. Biofunctional analysis of comprehensive mRNA expression. Intracellular mRNA expression in Res-HL60 cells was analyzed using Ingenuity ${ }^{\circledR}$ Pathway Analysis tools. Size and z-score are shown according to-log (p-value) and color, respectively (A), and size and z-score according to the number of genes and color, respectively, are shown (B). Orange and blue indicate higher and lower values, respectively.

regulation of VASP, $M X D 1, C C N D 1, H P G D$, and $T N F$ (Fig. 4). Therefore, similar expression patterns of these 7 mRNAs in Res-HL-60 were detected using both cDNA microarray and real-time RT-PCR.

Analysis of EVs in Res-HL60. To clarify whether these mRNAs were expressed in EVs, a mode of intercellular communication, EVs from Res-HL60 were analyzed. As EVs released from cells can be detected and harvested from cell culture supernatants, fetal EVs (i.e., from FBS) in cell culture must be eliminated before collecting EVs derived from Res-HL60 cells in vitro. The cell viability in FBS-free media and media with EV-free-FBS was analyzed to determine the optimal condition of cell culture which performs normal cellular metabolism without fetal EVs. Compared to standard FBS media, Res-HL60 and Wt-HL60 fared similarly with EV-free FBS media; however, the viability of HL60 decreased to $<20 \%$ by day 3 in FBS-free medium (Fig. 5). In addition, the cell growth abilities of Res-HL-60 and Wt-HL60 cells in EV-free FBS media were similar to that in standard FBS media (Fig. 6). Therefore, an analysis of mRNA expression in EVs from Res-HL60 was performed using cellular debris collected from cell culture supernatants on day 2. Five mRNAs, SEPT11, VASP, CCND1, HPGD and TNF, were detected in EVs from Wt-HL60; however, these molecules were not detected in EVs from Res-HL60 by either real-time RT-PCR or electropherogram (Fig. 7).

\section{Discussion}

In the present study, an analysis of the intracellular genetic network and transference potency of radio-resistant specific mRNAs between intercellular communicating EVs was performed via quantitative RNA analysis. Significantly changes in the expression of 7,309 known mRNAs were observed in Res-HL60 cells relative to Wt-HL60 cells; in particular, changes in the expression of protein ubiquitination pathwayrelated molecules was observed in Res-HL60 (Fig. 2). Protein 


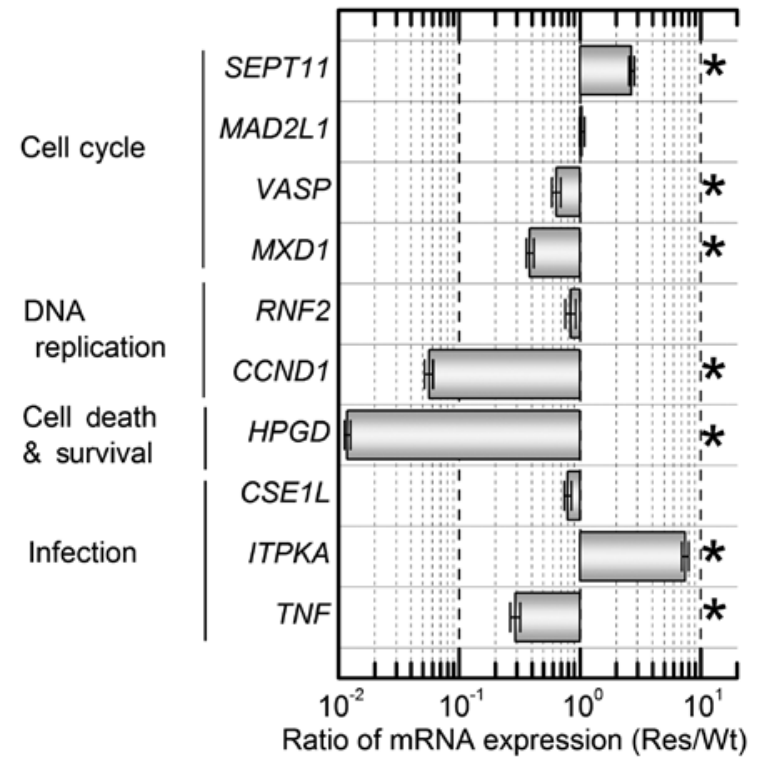

Figure 4. Quantitative analysis of mRNA expression in Res-HL60. mRNA expression in Res-HL60 was quantified using real-time RT-PCR with SYBR-Green fluorescence. Expression of each gene was compared as a ratio of (Res-HL60 cell expression)/(Wt-HL60 cell expression). Values are shown as means \pm standard errors of 3 separate experiments. $P<0.05$, Student's t-test.

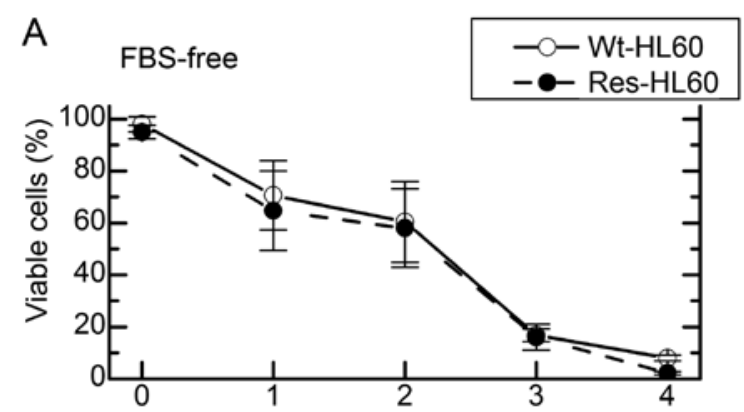

B EV-free-FBS

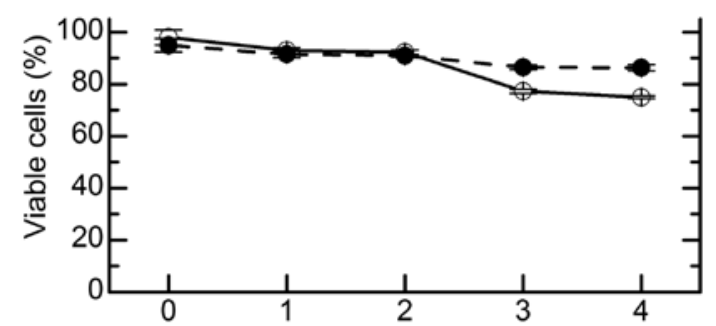

C Standard FBS

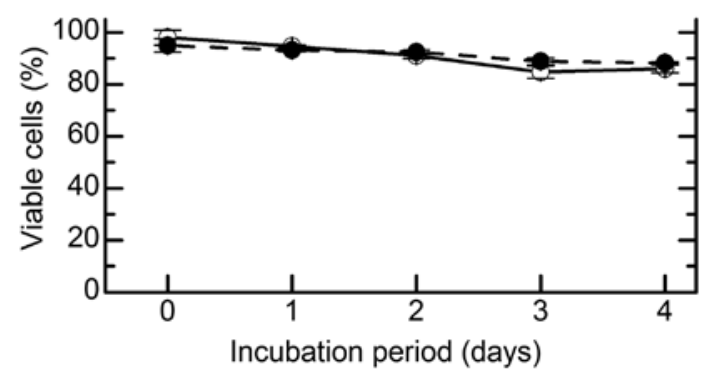

Figure 5. Analysis of HL60 cell viability under each FBS culture condition. Cultures in FBS-free (A), EV-free (B), or standard FBS (C) media were prepared to assess cell viability over a 4-day period. Viable cells were determined by Annexin V and propidium iodide double staining and flow cytometry. Values are shown as means \pm standard errors of 3 separate experiments.
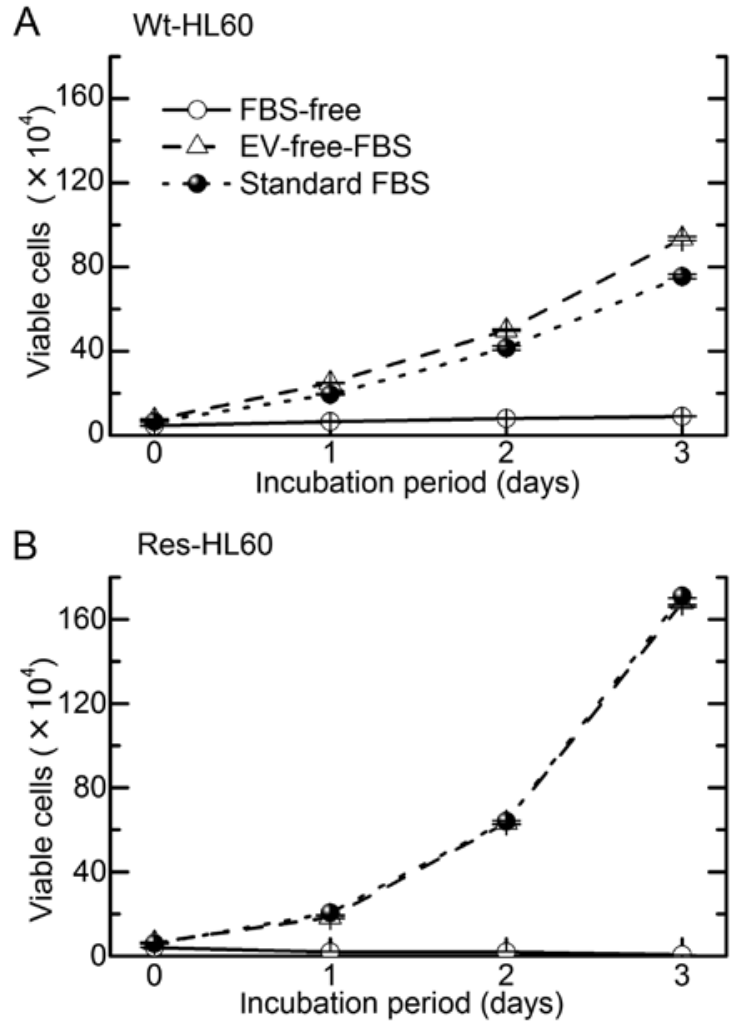

Figure 6. Cell growth analysis of HL60 cells cultured under various FBS conditions. Cells were cultured in FBS-free, EV-free, or standard FBS medium; cell growth curves of Wt-HL60 cells (A) and Res-HL60 cells (B) were estimated using trypan blue to distinguish between viable and damaged or dead cells. Values are shown as means \pm standard errors of 3 separate experiments.

ubiquitination, which serves as a cell signaling activator or suppressor in acute leukemia cells, maintaining DNA damage responses and tumorigenesis $(10,11)$. Res-HL60 may regulate tumorigenesis to a greater extent than Wt-HL60. Generally, reactive oxygen species or free radicals produced by IR, such as X-rays and gamma-rays, are known to indirectly and/or directly induce DNA strand breaks and to exert various cytotoxic effects $(12,13)$. Ai et al reported that ubiquitination of the cytokine receptor G-CSFR regulates myeloid cell survival and proliferation (14). Therefore, activation of the protein ubiquitination system via radiation reiteration exposure may affect the potency of radiation protection. In the category of ubiquitination-related biofunction, gene expression in the categories of 'cell cycle', 'DNA replication/repair', and 'infection' were found to correlate closely with Res-HL60. Among the 7 reproducibly identified mRNAs, SEPT11 and VASP are necessary for developing microtubules and cytoskeleton structures and are related to the G2/M transition (15-17). The Max protein, encoded by $M X D 1$, activates the transcription factor myc to form a Myc-Max heterodimer and thus promotes cell proliferation and/or transformation $(18,19)$. Therefore, our present data suggest that the behavior of cell cycle-related genes (up of SEPT11, down of VASP/MXD1) in Res-HL60 modify the intracellular environment, including cytoskeletal formation, whereas repeated exposure to IR suppresses Myc signaling. 


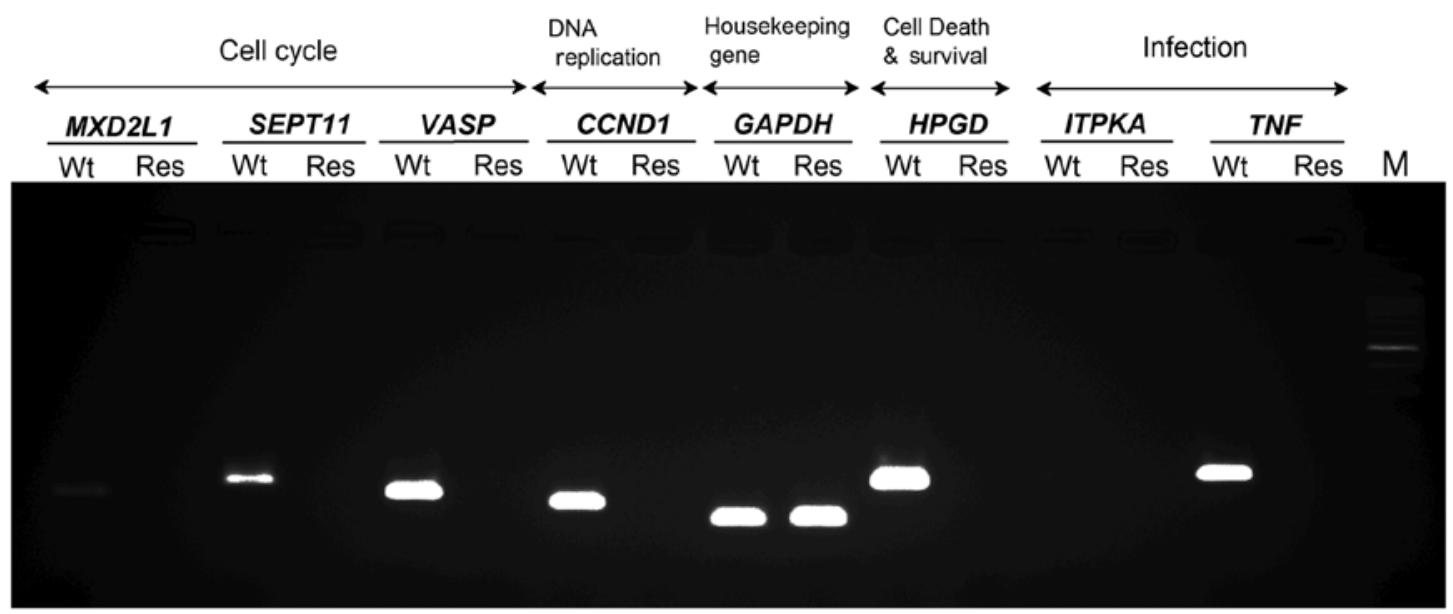

Figure 7. Analysis of mRNA expression in EVs. EVs released from each HL-60 cell type were isolated from cell culture medium via ultracentrifugation. Data are shown for cell cycle, DNA replication, housekeeping, cell death and survival, and infection-related genes.

On the contrary, the downregulation of CCND1, which encodes cyclin D1 and affects DNA replication and cell proliferation, was an unexpected phenomenon $(5,8,20)$. Shimura et al recently reported that repeated exposure to low-dose fractionated radiation abrogates cell cycle-dependent cyclin D1 degradation via the constitutive activation of AKT survival signaling in normal human fibroblasts (21). High- and low-dose radiation rates may induce different behaviors of some $C C N D 1$ gene regulators.

Xun et al reported that the rapid turnover of 15-PGDH, which is encoded by HPGD, in HL60 indicates that enzymatic activity depends on continued enzyme synthesis, which could be susceptible to hormone- and drug-controlled mechanisms. Upregulation of ITPKA, which promotes stem cell differentiation, and downregulation of $T N F$, which encodes a pro-inflammatory cytokine, were also observed (22-24). Therefore, these regulatory mechanisms may indicate the mechanism underlying radio-resistant APL. Interestingly, none of our target molecules were transferred among Res-HL60 cells via EVs. Accordingly, radio-resistant regulation in APL may be restricted to an intracellular phenomenon and may affect other cells. Szabó et al reported that in leukemic cells, the transfer of EVs and stimulating cytokines through intercellular interactions differs from inflammatory processes (25). It is necessary to confirm whether radio-resistant behavior can be countered by targeting the molecules identified in the present study. More precise approaches are required to elucidate the role of a genetic network in radio-resistant APL induced by exposure to repeated IR.

In conclusion, the specific phenomenon of radio-resistance acquisition is induced through changes of intracellular gene expression networks, but is not affected by the intercellular transfer of molecules.

\section{Acknowledgements}

This study was supported by a grant for Hirosaki University Young Institutional Research (2013-2015), the Takeda Science Foundation (2013 S.M.), and a KAKENHI Grant-in-Aid for Young Scientists (B) (no. 25861054 S.M.).

\section{References}

1. Russell JA, Irish W, Balogh A, Chaudhry MA, Savoie ML, Turner AR, Larratt L, Storek J, Bahlis NJ, Brown CB, et al: The addition of $400 \mathrm{cGY}$ total body irradiation to a regimen incorporating once-daily intravenous busulfan, fludarabine, and antithymocyte globulin reduces relapse without affecting nonrelapse mortality in acute myelogenous leukemia. Biol Blood Marrow Transplant 16: 509-514, 2010.

2. Termuhlen AM, Klopfenstein K, Olshefski R, Rosselet R, Yeager ND, Soni S and Gross TG: Mobilization of PML-RARA negative blood stem cells and salvage with autologous peripheral blood stem cell transplantation in children with relapsed acute promyelocytic leukemia. Pediatr Blood Cancer 51: 521-524, 2008.

3. Mikell JL, Waller EK, Switchenko JM, Rangaraju S, Ali Z, Graiser M, Hall WA, Langston AA, Esiashvili N, Khoury HJ, et al: Similar survival for patients undergoing reduced-intensity total body irradiation (TBI) versus myeloablative TBI as conditioning for allogeneic transplant in acute leukemia. Int J Radiat Oncol Biol Phys 89: 360-369, 2014.

4. Rashidi A and Fisher SI: Therapy-related acute promyelocytic leukemia: A systematic review. Med Oncol 30: 625, 2013.

5. Hazawa M, Hosokawa Y, Monzen S, Yoshino H and Kashiwakura I: Regulation of DNA damage response and cell cycle in radiation-resistant HL60 myeloid leukemia cells. Oncol Rep 28: 55-61, 2012.

6. Stein EM and Tallman MS: Acute promyelocytic leukemia in children and adolescents. Acta Haematol 132: 307-312, 2014.

7. Dalia SM, Horna P and Zhang L: Tetraploidy acute promyelocytic leuemia with double $\mathrm{t}(15 ; 17) / \mathrm{PML}-\mathrm{RARA}$, a case report with review of literature. Int J Clin Exp Pathol 7: 5363-5368, 2014.

8. Monzen S, Takimura K, Kashiwakura I and Hosokawa Y: Acute promyelocytic leukemia mutated to radioresistance suppressed monocyte lineage differentiation by phorbol 12-myristate 13-acetate. Leuk Res 37: 1162-1169, 2013.

9. Turturici G, Tinnirello R, Sconzo G and Geraci F: Extracellular membrane vesicles as a mechanism of cell-to-cell communication: Advantages and disadvantages. Am J Physiol Cell Physiol 306: C621-C633, 2014.

10. Zhao H, Zhu M, Dou G, Zhao H, Zhu B, Li J, Liao J and Xu X: BCL10 regulates RNF8/RNF168-mediated ubiquitination in the DNA damage response. Cell Cycle 13: 1777-1787, 2014.

11. Guan D, Factor D, Liu Y, Wang Z and Kao HY: The epigenetic regulator UHRF1 promotes ubiquitination-mediated degradation of the tumor-suppressor protein promyelocytic leukemia protein. Oncogene 32: 3819-3828, 2013.

12. Bajinskis A, Natarajan AT, Erixon $\mathrm{K}$ and Harms-Ringdahl $\mathrm{M}$ : DNA double strand breaks induced by the indirect effect of radiation are more efficiently repaired by non-homologous end joining compared to homologous recombination repair. Mutat Res 756: 21-29, 2013

13. Vignard J, Mirey G and Salles B: Ionizing-radiation induced DNA double-strand breaks: A direct and indirect lighting up. Radiother Oncol 108: 362-369, 2013. 
14. Ai J, Druhan LJ, Loveland MJ and Avalos BR: G-CSFR ubiquitination critically regulates myeloid cell survival and proliferation. PLoS One 3: e3422, 2008.

15. Hanai N, Nagata K, Kawajiri A, Shiromizu T, Saitoh N, Hasegawa Y, Murakami S and Inagaki M: Biochemical and cell biological characterization of a mammalian septin, Sept11. FEBS Lett 568: 83-88, 2004.

16. Tao Y, Chen YC, Sang JR and Xu WR: Phosphorylation of vasodilator stimulated phosphoprotein is correlated with cell cycle progression in HeLa cells. Mol Med Rep 3: 657-662, 2010.

17. Zhang YT, Xu LH,Lu Q, Liu KP,Liu PY,JiF,Liu XM, Ouyang DY and $\mathrm{He} \mathrm{XH}$ : VASP activation via the Go13/RhoA/PKA pathway mediates cucurbitacin-B-induced actin aggregation and cofilin-actin rod formation. PLoS One 9: e93547, 2014.

18. Nair SK and Burley SK: X-ray structures of Myc-Max and Mad-Max recognizing DNA. Molecular bases of regulation by proto-oncogenic transcription factors. Cell 112: 193-205, 2003.

19. Garcia-Sanz P, Quintanilla A, Lafita MC, Moreno-Bueno G, García-Gutierrez L, Tabor V, Varela I, Shiio Y, Larsson LG, Portillo F, et al: Sin3b interacts with Myc and decreases Myc levels. J Biol Chem 289: 22221-22236, 2014.
20. Pagano M, Theodoras AM, Tam SW and Draetta GF: Cyclin D1-mediated inhibition of repair and replicative DNA synthesis in human fibroblasts. Genes Dev 8: 1627-1639, 1994.

21. Shimura T, Kobayashi J, Komatsu K and Kunugita N: DNA damage signaling guards against perturbation of cyclin D1 expression triggered by low-dose long-term fractionated radiation. Oncogenesis 3: e132, 2014.

22. Sonnet M, Claus R, Becker N, Zucknick M, Petersen J, Lipka DB, Oakes CC, Andrulis M, Lier A, Milsom MD, et al: Early aberrant DNA methylation events in a mouse model of acute myeloid leukemia. Genome Med 6: 34, 2014.

23. Obeid LM, Linardic CM, Karolak LA and Hannun YA: Programmed cell death induced by ceramide. Science 259: 1769-1771, 1993

24. Xun CQ, Tian ZG and Tai HH: Stimulation of synthesis de novo of $\mathrm{NAD}(+)$-dependent 15-hydroxyprostaglandin dehydrogenase in human promyelocytic leukaemia (HL-60) cells by phorbol ester. Biochem J 279: 553-558, 1991.

25. Szabó GT, Tarr B, Pálóczi K, Éder K, Lajkó E, Kittel Á, Tóth S, György B, Pásztói M, Németh A, et al: Critical role of extracellular vesicles in modulating the cellular effects of cytokines. Cell Mol Life Sci 71: 4055-4067, 2014. 